\title{
Utrecht Yasa Bağlı Ruminasyon Ölçeği'nin (UYRÖ) Türkçe Versiyonunun Geçerlilik ve Güvenirliği
}

\author{
DOI: 10.26466/opus.550290 \\ Hasan Hüseyin Tekin*- Mehmet Kırlığlu** \\ ${ }^{*}$ Dr. Öğr. Üyesi, Necmettin Erbakan Üniversitesi, Sağlık Bilimleri Fak., Meram/Konya/ Türkiye \\ E-Posta: drhhtekin@gmail.com \\ ORCID: $\quad 0000-0002-6300-4098$ \\ ** Dr. Öğr. Üyesi, Necmettin Erbakan Üniversitesi, Sağlık Bilimleri Fak., Meram /Konya/Türkiye, \\ E-Posta: $\underline{\text { drkirlioglu@gmail.com }}$ \\ ORCID: $\quad \underline{0000-0003-0130-0841}$
}

\section{Öz}

Bu çalışmanın amacı yurt dışında geliştirilmiş olan Utrecht Yasa Bă̆lı Ruminasyon Ölçeği'ni (UYRÖ) Türk kültürüne uyarlamaktır. Ölçeğin geçerliliği için Doğrulayıcı Faktör Analizi (DFA) yapılmış ve yakınsak geçerlilik için Temel Yas Unsurları Ölçeği kullanılmıştır. Güvenirlik yöntemlerinden madde istatistikleri, Cronbach Alpha Katsayısından ve zamana karşı değişmezlik (test tekrar test) güvenirliğinden yararlanılmıştır. 15 madde ve beş alt faktörden oluşan UYRÖ'ye ilişkin model incelendiğinde $x^{2} / S d, C F I, I F I, R M S E A, S R M R$, PNFI ve PGFI uyum indekslerinin iyi düzeyde olduğu görülmüştür. Temel Yas Unsurları Ölçeği ile UYRÖ arasında pozitif yönlü, doğrusal ve istatistiksel olarak anlamlı bir ilişki bulunmuştur. Tüm maddelerin madde ölçek toplam korelasyon değerleri .30'un üstünde bulunmuştur. UYRÖ'nün Cronbach Alpha değeri .94 ve alt boyutlarm Cronbach Alpha değeri 80 ile 89 arasında değişmektedir. UYRÖ'nün zamana karşı değişmezliğini belirlemek amacıyla yapılan ön test - son test ölçümleri arasında pozitif yönlü, doğrusal ve istatistiksel olarak da anlamlı bir ilişki olduğu bulunmuştur ( $r=.89 ; p=.000)$. Sonuç: UYRÖ'nün geçerli ve güvenilir bir ölçüm aracı olduğu, zamansal olarak değişim göstermediği saptanmıştır.

Anahtar Kelimeler: Geçerlilik, Güvenirlilik, Ruminasyon, Yas 


\title{
Validaty and Reliability of the Turkish Version of the Utrecht Grief Rumination Scale
}

\begin{abstract}
The aim of this study is to adapt Utrecht Grief Rumination Scale, validity and reliability studies of which have already been done abroad, to Turkish culture. For the validity of the scale, Confirmatory Factor Analysis (CFA) were performed and the Core Bereavement Items was used for criterion validity. Among the reliability tests, material statistics and Cronbach's alpha coefficients were used. In order to test the invariance of time, the scale was applied to the same sample at four weeks intervals. It was found that $x^{2} / S d, C F I, I F I, R M S E A, S R M R$, PNFI and PGFI model fit indices were in good level. A statistically significant, positive and linear relation was found between The Core Bereavement Items and UGRS. The item-scale total correlation values of all items were above .30. The Cronbach's alpha value of the UGRS was .94 and the Cronbach's alpha of the sub-dimensions ranged from .80 to .89. A positive directional linear relationship was found between pre-test and post-test measurements to determine the invariance of UGRS $(r=.89 ; p=.000)$. Conclusion: As a result, it was determined that UGRS was valid and highly reliable and did not show any change in time.
\end{abstract}

Keywords: Validity, Reliability, Rumination, Grief 


\section{Giriş}

Ölüm nedeniyle bir yakınını kaybetmek evrensel bir insan deneyimidir. İnsanların çoğu bu duruma zihinsel veya fiziksel sağlık sorunları riskini arttıracak derecede acıyla tepki verirken, bir kısmı da profesyonel bir destek almadan bu stresli yaşam olayının üstesinden gelebilirler (Stroebe, Schut ve Stroebe, 2003). Sevilen birinin kaybının ardından görülebilen, psikolojik ve sosyal etkileri olan yas tepkileri, bir bireyin ömrü boyunca karşılaşabileceği en acı verici deneyimlerden biri olarak ifade edilebilir. Bu deneyim sürecini kimi bireyler çok kısa sürede atlatırken kimileri ise yıllarca atlatamaz (Selvi, Öztürk, Agargün, Besiroğlu ve Çilli, 2011). DSM-5 Tanı Ölçütleri Başvuru El Kitabı'na göre yas tutma belirtilerinin bireyin işlevselliğini bozacak şekilde en az bir yıl devam etmesi durumu "Kalıcı Komplike Yas Bozukluğu" (KKYB) olarak tanımlanır (American Psychiatric Association, 2013). Yas sürecinden sonra KKYB görülme sıklığ1 \%9.8'dir (Lundorff, Holmgren, Zachariae, FarverVestergaard ve O'Connor, 2017).

Bilişsel modele göre bütün psikiyatrik bozuklukların temel nedeni bireyin ruhsal durumu ve davranışlarını etkileyen çarpıtılmış veya işlevsel olmayan tekrarlayan düşüncelerdir. Özetle insanların duygu ve davranışları olayları nasıl yorumladıklarına bağlı olarak değişmektedir (Gülüm ve Dağ, 2012). Ölen kişi, kişinin ölümü ile ölüm süreci ve ölümün sonuçları hakkındaki tekrarlayan düşünceler akut yas sürecine özgüdür (Stroebe vd., 2007). Depresyonun ve karmaşık kederin gelişiminde ve devamında iki farklı ruminatif düşünce türü (depresif ruminasyon ve yasa bağlı ruminasyon) etkilidir (Clark ve Rhyno, 2007; NolenHoeksema, 2001). Yasa bağlı ruminasyon, kaybın sonuçları veya kayıpla ilgili olumsuz duygular hakkında tekrarlayan ve tekrarlanan düşünme olarak tanimlanır (Boelen, van den Bout ve van den Hout, 2003). Yasa bağlı ruminasyon, bir yakınını kaybeden bireylerde görülen ölüm sonrası yas ile yakından ilişkilidir (Eisma vd., 2013; Houwen, Stroebe, Schut, Stroebe ve van den Bout, 2010; van der Houwen, Stroebe, Schut ve Stroebe, 2010). Yasa bağlı ruminasyon, yas deneyiminden ve depresif ruminasyonundan farklıdır. Çünkü, yasa bağlı ruminasyonu yaşayan bireyler, ölümün ardından normal kabul edilen hüzün duygusunun dışında disfori, öfke ve kaygı gibi her biri ruminasyona işaret eden duy- 
gusal tepkileri yaşadıklarını belirtirler (Robinson ve Alloy, 2003; Sukhodolsky, Golub ve Cromwell, 2001).

$\mathrm{Bu}$ çalışmanın amacı yurt dışında geliştirilmiş olan Utrecht Yasa Bağlı Ruminasyon Ölçeği'ni (UYRÖ) Türk kültürüne uyarlayarak geçerlilik ve güvenirlik çalışması için gerekli analizleri yapmaktır.

Bugüne kadar uluslararası literatürde yas sürecine ilişkin çok sayıda çalışma yapılmış ve birçok ölçek geliştirilmiştir. Türkiye'de yas araştırmalarında kullanılmak üzere çeşitli ölçekler (Ayaz, Karanci ve Aker, 2014; Balcı-Çelik, 2006; Gökler-Danışman, Yalçınay ve Yıldız, 2017; Keser ve Işıklı, 2018; Yıldız ve Cimete, 2011) bulunmakla birlikte; ruminasyon ve yas üzerine geliştirilmiş veya uyarlanmış, geçerlilik ve güvenilirlik çalışması yapılmış herhangi bir ölçek yoktur. Bu nedenle, bu çalışma literatürdeki ve alandaki ihtiyacı gidermek açısından gerekli ve önemlidir.

\section{Yöntem}

\section{Örneklem}

Çalışma kapsamında amaçlı örneklem yöntemlerinden kartopu örneklem kullanılmıştır (Büyüköztürk, 2017; Patton, 2002; Yıldırım ve Şimşek, 2013). Son 36 ay (Doering, Barke, Friehs ve Eisma, 2018; Tang, Eisma, Li ve Chow, 2018) içerisinde çocuğunu, kardeşini veya annebabası gibi birinci dereceden bir yakınını kaybeden kişiler çalışmaya dâhil edilmiştir. Çalışma Selçuk Üniversitesi Sağlık Bilimleri Fakültesi ve Necmettin Erbakan Üniversitesi Sağlık Bilimleri Fakültesi'nde lisans eğitimi alan ve son 36 ay içerisinde birinci derece yakınını kaybetmiş kişiler ile başlamıştır. Görüşülen her katılımcıya 36 ay içerisinde birinci derece yakınını kaybetmiş başka bir kişiyi tanıyıp tanımadığı sorulmuş ve böylece örneklem kartopu yöntemi kullanılarak büyütülmüştür. Araştırmaya katılmayı kabul eden kişilerin e-postalarına veya whatsapp uygulamalarına surveey.com üzerinde hazırlanan veri toplama araçlarının linki gönderilmiştir. Link gönderiminden önce katılımcılara araştırmanın amacı ve yöntemi hakkında bilgi verilmiş ve katılımcıların sözel onamları alınmıştır. Ayrıca bilgilendirme ve onam formu online web tabanının ilk sayfasına konulmuş ve katılımcılara "devam" butonu- 
na basmaları durumunda "Bilgilendirilmiş Gönüllü Onam Formu"nu okuyup kabul etikleri belirtilmiştir. Bu şekilde ulaşılan 207 katılımcı ile DFA ve güvenirlik analizleri yapılmıştır. 103 katılımcı ile yakınsak geçerlilik ve son olarak 50 katılımc ile zamana karşı değişmezlik analizleri yapılmıştır. Bir analize dahil edilen katılımcı diğer analizlere dahil edilmemiştir. Katılımcılara ait bilgiler Tablo 1'de yer almaktadır.

Tablo 1: Katılımcılara ait bilgiler

\begin{tabular}{|c|c|c|c|c|c|c|c|}
\hline & & \multicolumn{2}{|c|}{207} & \multicolumn{2}{|c|}{103} & \multicolumn{2}{|c|}{50} \\
\hline & & $\mathbf{n}$ & $\%$ & $\mathbf{n}$ & $\%$ & $\mathbf{n}$ & $\%$ \\
\hline \multirow{2}{*}{ Cinsiyet } & Kadın & 148 & 71.5 & 68 & 66.02 & 29 & 58 \\
\hline & Erkek & 59 & 28.5 & 35 & 33.08 & 21 & 42 \\
\hline \multirow{5}{*}{ Eğitim Durumu } & İlkokul & 12 & 5.8 & 5 & 4.9 & 3 & 6 \\
\hline & Ortaokul & 14 & 6.8 & 6 & 5.8 & 12 & 24 \\
\hline & Lise & 75 & 36.2 & 23 & 22.3 & 15 & 30 \\
\hline & Lisans & 85 & 41.1 & 68 & 66.0 & 17 & 34 \\
\hline & Lisansüstü & 21 & 10.1 & 1 & 1.0 & 3 & 6 \\
\hline \multirow{2}{*}{$\begin{array}{l}\text { Medeni } \\
\text { Durumu }\end{array}$} & Bekar & 141 & 68.1 & 80 & 77.7 & 33 & 66 \\
\hline & Evli & 66 & 31.9 & 23 & 22.3 & 17 & 34 \\
\hline \multirow{7}{*}{$\begin{array}{l}\text { Kaybedilen } \\
\text { Kişinin } \\
\text { Ölüm Nedeni }\end{array}$} & $\begin{array}{l}\text { Ani gelişen tıbbi du- } \\
\text { rum (kalp krizi, beyin } \\
\text { kanaması vb.) }\end{array}$ & 68 & 32.4 & 34 & 33.0 & 20 & 40 \\
\hline & İntihar & 12 & 6.3 & 4 & 3.9 & 3 & 6 \\
\hline & Trafik kazası & 29 & 14.0 & 15 & 14.6 & 12 & 24 \\
\hline & İş kazası & 17 & 8.2 & 6 & 5.8 & 2 & 4 \\
\hline & Cinayet & 7 & 3.4 & 1 & 1.0 & 2 & 4 \\
\hline & Yaşlılık nedeniyle & 42 & 20.3 & 33 & 32.0 & 10 & 20 \\
\hline & Kanser & 32 & 15.4 & 10 & 9.7 & 1 & 2 \\
\hline \multirow{4}{*}{$\begin{array}{l}\text { Kaybedilen } \\
\text { Kişiye Yakınlık }\end{array}$} & Ebeveyn & 97 & 46.8 & 80 & 77.6 & 19 & 38 \\
\hline & Çocuk & 25 & 12.1 & 1 & 1.0 & 6 & 12 \\
\hline & Kardeş & 48 & 23.2 & 18 & 17.5 & 13 & 26 \\
\hline & Eş & 37 & 17.9 & 4 & 3.9 & 12 & 24 \\
\hline
\end{tabular}

DFA analizlerine dahil edilen 207 katılımcının yaş ortalaması $26.70 \pm 10.08$ 'dir (en küçük yaş 16 ve en büyük yaş 68). Ayrıca katılımcların yaşadıkları kaybın üzerinden geçen ortalama süre $13.32 \pm 10.19$ aydır. Yakınsak geçerlilik analizlerine dahil edilen 103 katılımcının yaş ortalaması $24.32 \pm 8.99^{\prime}$ dur (en küçük yaş 16 ve en büyük 
yaş 60). Ayrıca katılımcıların yaşadıkları kaybın üzerinden geçen ortalama süre $13.78 \pm 10.43$ aydır. Zamana karşı değişmezlik analizlerine dahil edilen 50 katılımının yaş ortalaması $28.50 \pm 10.36$ 'dır (en küçük yaş 18 ve en büyük yaş 68). Ayrıca katılımcıların yaşadıkları kaybın üzerinden geçen ortalama süre $12.89 \pm 10.18$ aydır.

\section{Veri Toplama Araçları}

\section{Utrecht Yasa Bağhı Ruminasyon Ölçeği (UYRÖ)}

Türkçe'ye Utrecht Yasa Bağlı Ruminasyon Ölçeği (UYRÖ) olarak çevrilen Utrecht Grief Rumination Scale (UGRS) Eisma ve diğerleri (2014) tarafından geliştirilmiş bir ölçektir (Eisma vd., 2014). Ölçek kaybın nedenleri ve sonuçları ile ilgili olumsuz duygular hakkında tekrarlayan, tekrarlayıcı ve öz-odaklı düşünceler olarak tanımlanan yas ruminasyonunu ölçmek için kullanılmaktadır. UYRÖ 15 maddeden oluşmaktadır. 5'li likert tipi bir ölçektir. Ölçekteki maddelere verilen cevaplarda 1 "Hiç" anlamına gelmekte iken 5 "Çok Sık" anlamına gelmektedir. Ölçeğin hem toplam hem de alt boyutlarına ilişkin puan hesaplaması bulunmaktadır. 1, 2, 15 maddeler (Son bir ay süresince onun ölümünün sizin yaşamınıza etkisini ne sıklıkla düşündünüz) yaşanan kaybın sonuçları ve anlamı hakkında düşüncelere; 3, 9, 14 maddeler (Son bir ay süresince aile üyelerinden gereken desteği alıp almadığınızı ne sıklıkla sorguladınız) sosyal destek hakkındaki düşüncelere; 4, 8, 10 maddeler (Son bir ay süresince onun ölümünü önleyip önleyemeyeceğinizi ne sıklıkla düşündünüz) ya şöyle olsaydı sorulara (ölüme sebep veren olaylara ilişkin karşıt düşüncelere); 5, 11, 12 maddeler (Son bir ay süresince bu kaybı hak edecek ne yaptığınızı kendinize ne sıklıkla sordunuz) neden sorularına (ölümünü adaletsiz oluşu ile ilgili düşüncelere); 6, 7, 13 maddeler (Son bir ay süresince bu kayıp hakkında tam olarak ne hissettiğinizi ne sıklıkla düşündünüz) duygular hakkındaki düşüncelere (kayıpla ilgili negatif duygusal tepkileri) ilişkin alt boyutları kapsamaktadır. Alt boyutlar sırasıyla Anlam, İlişkiler, Karşıt Olgular, Adaletsizlik ve Tepkiler olarak adlandırılmaktadır. Ölçekte ters kodlanan madde bulunmamaktadir. 
Ölçeğin özgün formuna ait iç tutarlılığının $(\alpha=.90)$ ve alt boyutların güvenirlik analizlerinin (Tepkiler $\alpha=.84$; Adaletsizlik $\alpha=.88$; Karşıt Olgular $\alpha=.89$; Anlam $\alpha=.84$; İlişkiler $\alpha=.74$ ) iyi düzeyde olduğu bulunmuştur.

\section{Temel Yas Unsurları Ölçeği (TYUÖ)}

Burnett ve arkadaşları tarafından 1997 yılında Avustralya'da geliştirilen Temel Yas Unsurları Ölçeği'nin (Core Bereavement Items) Türkçe uyarlaması Selvi ve arkadaşları tarafından yapılmıştır (Selvi vd., 2011). Sevdiği bir yakınını kaybetmiş bireylerdeki (örneğin eşini kaybetmiş bireyler, çocuğunu kaybetmiş ebeveynler, anne ya da babasını kaybetmiş yetişkinler) yasın şiddetini değerlendiren bir ölçektir. Bu ölçek 17 maddeden oluşmuştur. Dört puanlı Likert çizelgesi kullanılmıştır: Süreklidaima-her defasında: 3 puan; Çoğunlukla: 2 puan; Bazen: 1 puan; Hiçbir zaman: 0 puandır. Üç alt boyutu bulunmaktadır: imajlar ve düşünceler, 7 sorudan oluşur. Ölen kişiyle ilgili hayaller ve düşüncelerle ilgili sorular bulunur. Akut ayrılık, 5 sorudan oluşur. Hasret, özlem, kayıp gerçeğiyle yüzleşmek gibi soruları içerir. Keder, 5 sorudan oluşur. Ölen kişiyi hatırlatıcı durumlar ayrı ayrı irdelenir. Ölçeğin orijinalinde: 1'den 17'ye kadar toplam puan aralığı 0-51, $\alpha=.91$; 1'den 7'ye kadar imajlar ve düşünceler kategorisinde puan aralığ1 0-21, $\alpha=.74 ; 8$ 'den 12'ye kadar akut ayrılık kategorisinde puan aralığ $0-15, \alpha=.77 ; 13^{\prime}$ ten $17^{\prime}$ ye kadar keder kategorisinde puan aralığı $0-15, \alpha=.86^{\prime}$ dır. Yüksek puanlar yasın daha yoğun yaşandığını göstermektedir (Selvi vd., 2011).

\section{İşlem}

Çalışmaya başlamadan önce Necmettin Erbakan Üniversitesi Sosyal ve Beşeri Bilimler Etik Kurulu'nun 18.01.2019 tarih ve 2019/1 sayılı kararı ile çalışmanın yapılmasında herhangi bir etik sorun olmadığına, çalışmanın etik açıdan uygun olduğuna dair yazılı onay belgesi alınmıştır.

Ölçeğin psikometrik özelliklerini belirlemek için çalışma grubuna son şekli verilen ölçek formu uygulanmıştır. DFA ile önceden belirlenmiş bir yapının doğrulanması yapılmakta ve özellikle uyarlama çalışmalarında kullanılması önerilmektedir. DFA var olan yapının uygunluğunun test edilmesi için kullanışlı bir analizdir (Çapık, 2014; Seçer, 2015; Seçer, 2017; 
Sümer, 2000). AFA ile orijinal ölçeğin yapısı bozulabilmektedir. Farklı kültürlerde uyarlaması yapılan ölçeğin İngilizce, Almanca ve Çince versiyonlarında da benzer yol izlenmiştir (Doering vd., 2018; Eisma vd., 2014; Tang vd., 2018). Bu nedenle Eisma ve diğerleri (2014) tarafından ortaya konan yapının Türk kültüründe doğrulanıp doğrulanmayacağını belirlemek üzere birinci ve ikinci düzey DFA yapılmıştır. Bir ölçeğin alt boyutlara ilişkin toplam puanı söz konusu ise birinci düzey DFA, ölçeğin toplam puanı söz konusu ise mutlaka ikinci düzey DFA'nın yapılması gerektiği belirtilmektedir (Karagöz, 2016; Seçer, 2015). DFA'nın değerlendirilmesinde hangi uyum indekslerinin geçerli olması gerektiği konusunda altın bir kuraldan bahsedilemediği için (Crowley ve Fan, 1997; Munro, 2005) çalışma kapsamında ölçeğin Felemenkçe, İngilizce, Almanca ve Çince versiyonlarında kullanılmış olan ortak uyum indeksleri ile örneklem büyüklüğü ve parametre tahminlerinden etkilenmeyen uyum indeksleri tercih edilmiştir. Bu uyum indeksleri $\mathrm{x}^{2} / \mathrm{sd}, \mathrm{CFI}, \mathrm{RMSEA}$ (Doering vd., 2018; Eisma vd., 2014; Tang vd., 2018) ile SRMR, IFI, PNFI ve PGFI'dır (Hooper, Coughlan, Mullen ve 2008). CFI ve IFI indeksleri için kabul edilebilir uyum değeri .90 ve mükemmel uyum değeri 0.95 olarak kabul edilmektedir. RMSEA için ise kabul edilebilir uyum değeri .10 ve mükemmel uyum değeri .5 olarak kabul edilmektedir. RMR için kabul edilebilir uyum değeri 1.0 ve mükemmel uyum değeri .08 olarak kabul edilmektedir. SRMR için kabul edilebilir uyum değeri .05-.10 ve mükemmel uyum değeri .00-.05 olarak kabul edilmektedir. PNFI, PGFI indeksleri için kabul edilebilir uyum değeri ve mükemmel uyum değeri $>.50$ kabul edilmektedir (Hoe, 2008; Hooper vd., 2008; Munro, 2005; Schreiber, Nora, Stage, Barlow ve King, 2006). Yakınsak geçerlilik için ise Utrecht Yasa Bağlı Ruminasyon Ölçeği ile Temel Yas Unsurları Ölçeği arasındaki korelasyonlar hesaplanmıştır. Ayrıca UYRÖ'nün zamana karşı değişmezliğini belirlemek amacıyla dört hafta ara ile yapılan ön test ve son test ölçümleri arasındaki korelasyonlar hesaplanmıştır.

\section{Verilerin Analizi}

Veri analizleri için IBM SPSS 20.0 ve LISREL 8.80 paket programları kullanılmıştır. IBM SPSS 20.0 programı ile Kendall Uyuşum Katsayısı (Wa), normallik testi, korelasyon analizi, iç tutarlılık ve madde analizleri 
yapılmıştır. LISREL 8.80 programı ile de DFA yapılmıştır. Ölçekten alınan puanların parametrik analizlere uygun olup olmadığının değerlendirilmesi için normallik testi yapılmıştır. Bu noktada gruplara düşen kişi sayısı 200 ve üzerinde ise Kolmogorov-Smirnov test sonuçlarına, 200 'ün altında ise Shapiro-Wilk testi sonuçlarına bakılmıştır. Her üç veri setinin normal dağılım testi $p<0,05$ şeklinde anlamlı çıkmıştır. Bu nedenle Skewness ve Kurtosis değerleri incelenmiş olup Skewness ve Kurtosis değerlerinin $+1,5$ ile $-1,5$ arasında (Tabachnick ve Fidell, 2007) olduğu tespit edildiğinden verilerin normal dağıldığı sonucuna ulaşılmıştır. Veri setinde kayıp veri bulunmamaktadır.

\section{UYRÖ’nün Geçerlilik Analizleri}

\section{Dil Geçerliliği}

İlk olarak ölçeğin Türkçe versiyonun oluşturulabilmesi için ölçek sahibi Maarten C. Eisma'dan yazılı izin alınmıştır. Dil geçerliliği dört aşamada gerçekleştirilmiştir. Birinci aşamada öncelikli olarak UYRÖ'nün maddeleri iki farklı yeminli tercüman tarafından Türkçe'ye çevrilmiştir. Bu kapsamda en az iki bağımsız çevirmenin olması vurgulanmaktadır (Aksayan ve Gözüm, 2002). İkinci aşamada İngilizce ifadelerin altında Türkçe ifadeler olacak şekilde form hazırlanmıştır. Hazırlanan form doktora düzeyinde ve daha önce yas süreci ile ilgili çalışmaları bulunan yedi akademisyene gönderilmiştir. Ayrıca, bu akademisyenlerden ikisi son 18 ay içerisinde yakınını kaybetmiştir. Bir akademisyen de İngilizce diline ek olarak Felemenkçe dilini bilmektedir. Yedi akademisyenden gelen düzeltmeler araştırmacılar tarafından karşılaştırılmış ve söz konusu maddeyi en iyi ifade ettiği düşünülen çeviriler benimsenmiştir (Seçer, 2015; Seçer, Halmatov ve Gençdoğan; 2013). Üçüncü aşamada nihai Türkçe form Türk Dili ve Edebiyatı Bölümünde doktora düzeyinde eğitime sahip iki akademisyene gönderilmiş (Aksayan ve Gözüm, 2002; Seçer, 2015) ve dördüncü aşamada bu akademisyenlerden gelen düzeltmeler yapıldıktan sonra UYRÖ'nün Türkçe versiyonu kapsam geçerliliği için alandan 10 akademisyene gönderilmiş, akademisyenlerden her bir ölçek maddesini 1-10 puan aralığındaki puanlar üzerinden değerlendirmeleri istenmiştir. Akademisyen görüşlerinin sonuçları doğrultusunda 
Kendall Uyuşum Katsayısı (Kendall Coefficient of ConcordanceKendall's W) korelasyon testi uygulanmış ve akademisyenler arasında istatistiksel olarak anlamlı bir fark bulunmamıştır (Kendall's W=.095, $\mathrm{p}=.265 ; \mathrm{p}>.05$, ki-kare: 11.153). Bu sonuçlar akademisyen görüşleri arasında uyum olduğunu göstermektedir.

\section{Doğrulayıcı Faktör Analizi}

Doğrulayıcı faktör analizinde UYRÖ Türkçe formunun beş faktörlü modelinin uyum indeksleri incelenmiştir. Birinci düzey DFA'ya ilişkin veriler Şekil 1 ve 2'de ve İkinci düzey DFA'ya ilişkin veriler Şekil 3'de görüldüğü gibidir.

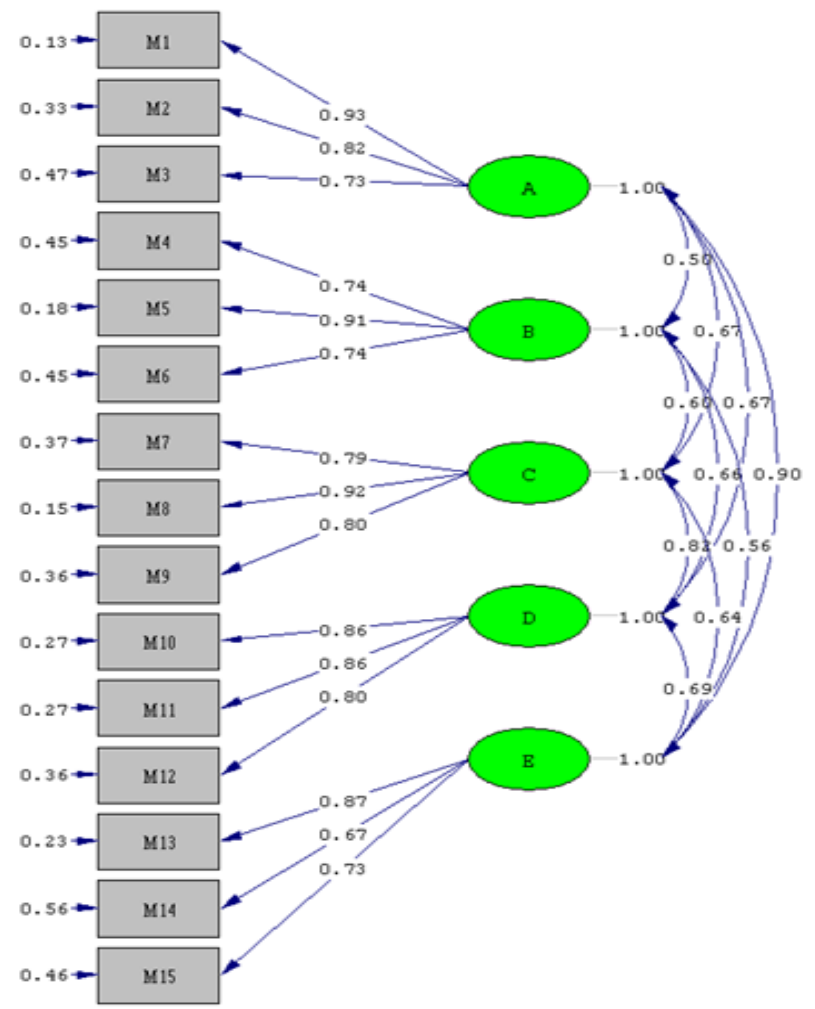

Şekil 1. Beş Faktörlü ve 15 Maddelik UYRÖ'ye İlişkin Birinci Düzey DFA Sonuçları 
Ölçeğin faktör yapısına ilişkin olarak elde edilen 15 madde ve beş faktörlü yapının model uyumunun ( $\chi 2=120.57, \mathrm{sd}=80, \chi 2 / \mathrm{sd}=1.51)$ ve model uyum indekslerinin kabul edilebilir sinırlar üzerinde olduğu görülmektedir (RMSEA=.05, SRMR= .04, CFI=.99, IFI=.99, PNFI= .74, PGFI $=.62)$.

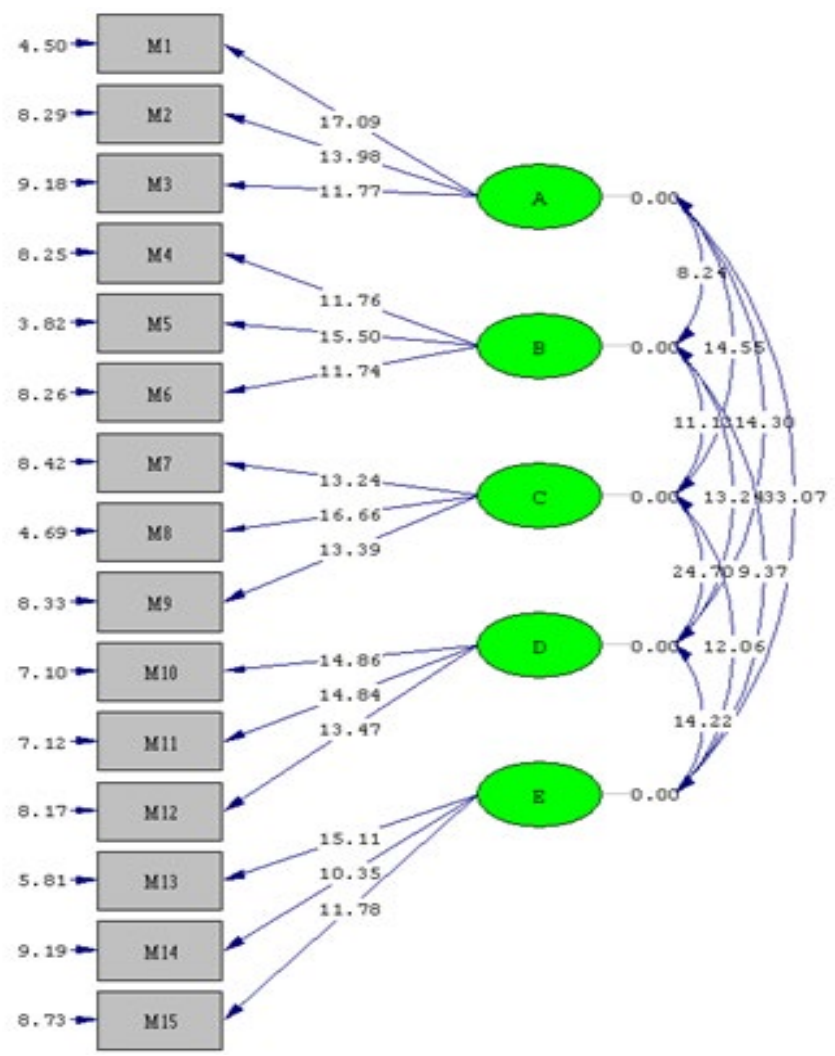

Şekil 2: Beş Faktörlü ve 15 Maddelik URYÖ'ye İlişkin Birinci Düzey DFA Sonuçlarının T Değerleri

Modeldeki path diyagramındaki t değerleri incelenmiştir. Modeldeki path diyagramındaki t değerlerinin 1.96 'yı aştığı ve en az .05 düzeyinde anlamlı olduğu tespit edilmiştir $(\mathrm{p}<0.01)$. 


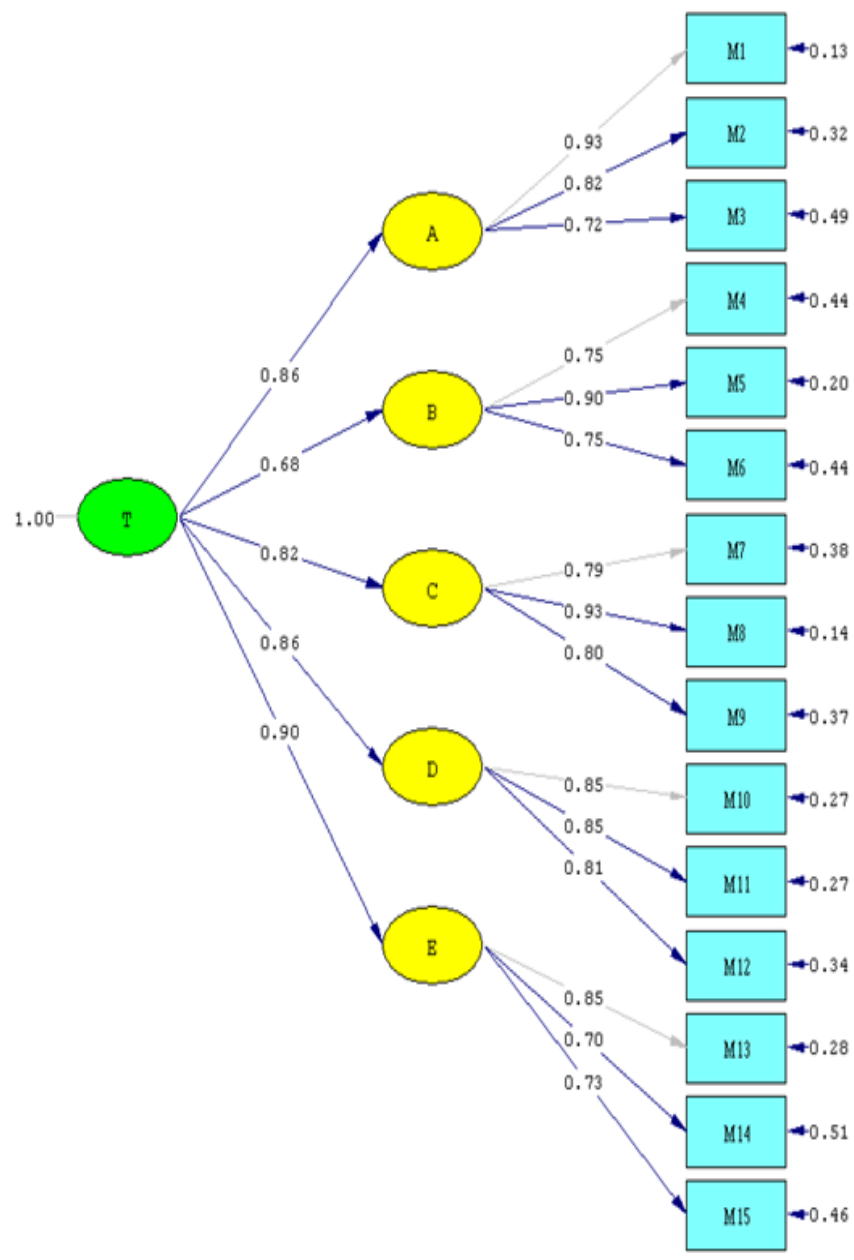

Şekil 3: Beş Faktörlü ve 15 Maddelik UYRÖ'ye İlişkin İkinci Düzey DFA Sonuçları

Ölçeğin faktör yapısına ilişkin olarak elde edilen 15 madde ve beş faktörlü yapının model uyumunun $\left(X^{2}=200.51 \mathrm{sd}=85, X^{2} / \mathrm{sd}=2.36\right)$ ve model uyum indekslerinin kabul edilebilir sinırların üstünde olduğu görülmektedir (RMSEA=.08, SRMR= .06, CFI=.98, IFI= .98, PNFI= .78, PGFI= .63). DFA analizine dahil edilen 207 katılımcının ölçekten aldıkları ortalama puan $43.01 \pm 15.29$ 'dir (en küçük puan 15 en yüksek puan $75^{\prime}$ dir). 


\section{Yakınsak geçerlilik}

UYRÖ $(43.21 \pm 16.25)$ ile TYUÖ $(46.30 \pm 13.18)$ arasında pozitif yönlü doğrusal bir ilişki olduğu istatistiksel açıdan ortaya konmuştur ( $\mathrm{r}=.761$; $\mathrm{p}=.000)$.

\section{UYRÖ'nün Güvenirlik Analizleri}

UYRÖ'nün güvenirliğini incelemek için iç tutarlılık, madde analizleri ve test-tekrar-test güvenirlik analizleri uygulanmıştır. Ölçeğin iç tutarlılık katsayısı $\alpha=.94$ ve alt boyutların iç tutarlık katsayısı $\alpha=.86$ (Anlam); $\alpha=.83$ (Illişkiler); $\alpha=.87$ (Karşıt Olgular); $\alpha=.89$ (Adaletsizlik); $\alpha=.80$ (Tepkiler) olarak tespit edilmiştir. Madde-toplam korelasyon değerlerinin .59 ile .76 arasında olduğu ve herhangi madde çıkarıldığında iç tutarlık katsayısının .92 ile .93 arasında değiştiği görülmüştür. UYRÖ'nün zamana karşı değişmezliğini belirlemek amacıyla dört hafta ara ile yapılan ön test $(43.68 \pm 17.71)$ ve son test $(42.20 \pm 15.09)$ ölçümleri arasında pozitif yönlü doğrusal bir ilişki olduğu ve bu ilişki istatistiksel olarak da anlamlı bulunmuştur ( $\mathrm{r}=.89 ; \mathrm{p}=.000)$.

\section{Tartışma ve Sonuç}

UYRÖ'nün Türk kültürüne uyarlanması için yapılan bu çalışmada ölçeğin hem alt boyutlarının hem de toplam puanının olması nedeniyle birinci ve ikinci düzey DFA yapılmıştır. Birinci ve ikinci düzey DFA sonuçlarına ilişkin ölçeğin model uyumunun ve model uyum indekslerinin kabul edilebilir sınırların üstünde olduğu tespit edilmiştir. Ayrıca ölçeğin İngilizce, Felemenkçe, Almanca ve Çince (Doering vd., 2018; Eisma vd., 2014; Tang vd., 2018) versiyonlarını birinci ve ikinci düzey DFA sonuçları ile karşılaştıııldığında elde edilen verilerin benzer olduğu söylenebilir. Yakınsak geçerlilikte UYRÖ ile TYUÖ arasındaki korelasyona bakılmıştır. Korelasyon katsayısı .70'in üzerinde ise bunun unsurlar arasında kuvvetli bir ilişki olduğu anlamına geldiği belirtilmektedir (Durmuş, Yurtkoru ve Çinko, 2011). Elde edilen bulgular UYRÖ'nün TYUÖ ile iyi düzeyde korelasyona sahip olduğunu göstermektedir. 
İç tutarlılık katsayısının .70'in üzerinde olması ölçeğin oldukça yüksek güvenirliğe sahip olduğunu belirtmektedir (Büyüköztürk, 2017; Pallant, 2010). Ölçek ve alt boyutlarının iç tutarlık katsayılarının .70'in üzerinde olduğu ve ayrıca İngilizce, Felemenkçe, Almanca ve Çince (Doering vd., 2018; Eisma vd., 2014; Tang vd., 2018) versiyonlarından daha yüksek bir iç tutarlığa sahip olduğu görülmektedir. Literatürde madde toplam korelasyonlarının .30 'un üzerinde olması istenmektedir (Büyüköztürk, 2017; Pallant, 2010). Çalışmamızda madde-toplam korelasyon değerlerinin .30 üzerinde olduğu ve ölçeğin diğer dillerdeki uyarlama çalışmaları ile benzerlik gösterdiği tespit edilmiştir (Balc1-Çelik, 2006; Tang vd., 2018; Yıldız ve Cimete, 2011). Zamana karşı değişmezlik çalışmasında dört hafta ara ile yapılan ön test ve son test ölçümleri arasındaki korelasyona bakılmıştır. Korelasyon katsayısı .70'in üzerinde ise unsurlar arasında kuvvetli bir ilişki olduğu anlamına geldiği belirtilmektedir (Durmuş vd., 2011). Elde edilen bulgular ön test ve son test ölçümler arasında iyi düzeyde korelasyonun olduğunu ve UYRÖ'nün zamana karşı değişim göstermeğini belirtmektedir.

Sonuç olarak, UYRÖ ile ilgili yapılan geçerlilik ve güvenirlik analizlerinin literatürdeki istenilen değerleri karşıladığı, geçerli ve güvenilir bir ölçüm aracı olduğu, zamansal olarak değişim göstermediği bilimsel veriler ışı̆̆ında gösterilmiştir. Bu çalışma ile Türkiye'de yasa bağlı ruminasyonu ve yasın şiddetini değerlendirebilecek bir ölçüm aracı literatüre kazandırılmıştır. UYRÖ'nün yas ve kederle ilgili çalışmalarda kullanılması eş, çocuk, kardeş, ebeveyn gibi sevdiği bir yakınını kaybeden yas sürecindeki bireylerin yasa bağlı ruminatif tekrarlayıcı düşünce örüntülerini ve yas süreçlerinin şiddetini değerlendirebilmek açısından önemlidir. UYRÖ yasla ilgili çalışmalarda kullanmak ve yas şiddetini belirlemek için uygun psikometrik özellikleri taşımaktadır. Bu ölçek Türkiye'de ileride yapılacak yas, keder ve ruminatif yas çalışmalarında güvenle kullanılabilecek bir ölçüm aracıdır. Söz konusu ölçeğin klinik olmayan örneklemde çalışılmış olması elde edilen bilgileri sınırlamaktadır. Bu nedenle, ilerleyen süreçte klinik gruplarla çalışılarak bu ölçeğin sevdiği bir yakınını kaybetmiş bireylerden oluşan klinik örneklemler üzerinden de doğrulanması önerilmektedir. 


\title{
EXTENDED ABSTRACT
}

\section{Validaty and Reliability of the Turkish Version of the Utrecht Grief Rumination Scale}

\author{
Hasan Hüseyin Tekin - Mehmet Kırlığlu \\ Necmettin Erbakan University
}

Losing a relative because of death is a universal human experience. While most people respond to this situation in a way that increases the risk of mental or physical health problems, some can overcome this stressful incident without any professional support (Stroebe, Schut and Stroebe, 2003). The grief reactions, which can be seen after the loss of a loved one, having psychological and social effects, can be expressed as one of the most painful experiences that an individual can encounter during his or her life. While some individuals overcome in a very short period of time, others cannot for years (Selvi, Öztürk, Agargün, Besiroğlu and Çilli, 2011).

The aim of this study is to adapt the Utrecht Grief Rumination Scale (UGRS) to Turkish culture and to make the necessary analyzes for validity and reliability study. To date, numerous studies have been conducted in the international literature on grief and many scales have been developed. Although there are various scales (Ayaz, Karanci and Aker, 2014; Balcı-Çelik, 2006; Gökler-Danışman, Yalçınay and Yıldız, 2017; Keser and Işıklı, 2018; Yıldız and Cimete, 2011) to be used in grief research in Turkey; there is no scale which has been developed or adapted on rumination and grief and has been validated for reliability and validity. Therefore, this study is necessary and important in terms of fulfilling this need in the literature and field.

In the study, snowball sampling was used for purposive sampling methods (Büyüköztürk, 2017; Patton, 2002; Yıldırım and Şimşek, 2013). Individuals who lost their first-degree relatives such as child, sibling or parents in the last 36 months (Doering, Barke, Friehs ve Eisma, 2018; Tang, Eisma, Li ve Chow, 2018) were included in the study. Each participant was asked if he / she knew another person who lost his / her first 
degree relative within 36 months and thus the sample was expanded using the snowball method. CFA and reliability analyzes were performed with 207 participants. Convergent validity was analyzed with 103 participants and invariance analysis was conducted with 50 participants. The participant included in an analysis was not included in other analyzes. The average age of 207 participants included in the CFA analysis was $26.70 \pm 10.08$ (minimum age 16 and maximum age 68). The average time over the loss experienced by participants was $13.32 \pm 10.19$ months. The average age of the 103 participants included in the convergent validity analyzes was $24.32 \pm 8.99$ (minimum age 16 and maximum 60 ). The average time over the loss experienced by participants was $13.78 \pm 10.43$ months. The average age of 50 participants included in the invariance analysis was $28.50 \pm 10.36$ years (minimum age 18 and maximum 68). The average time over the loss experienced by participants was $12.89 \pm 10.18$ months. Utrecht Grief Rumination Scale and Core Bereavement Items were used as data collection tool. After the validity of the scale's language, the confirmatory factor analysis and the fit index of the five-factor model of the Turkish version of the UGRS were examined

IBM SPSS 20.0 and LISREL 8.80 packet programs were used for data analysis.

Regarding the factor structure of the scale (first level CFA), it is observed that the model fit $(\chi 2=120.57, \mathrm{sd}=80, \chi 2 / \mathrm{sd}=1.51)$ and model fit indices of 15 items and five factor structure obtained are above acceptable limits (RMSEA=.05, SRMR=.04, CFI=.99, IFI=.99, PNFI= .74, PGFI= .62). $T$ values in the path diagram in the model are examined. The $t$ values in the path diagram of the model were found to be more than 1.96 and significant at the .05 level $(\mathrm{p}<0.01)$. Regarding the factor structure of the scale (second level CFA), it is observed that 15 items and five factor structure model fit $(\mathrm{X} 2=200.51 \mathrm{sd}=85, \mathrm{X} 2 / \mathrm{sd}=2.36)$ and model fit indexes are above acceptable limits (RMSEA $=.08$, SRMR $=.06, \mathrm{CFI}=.98$, $\mathrm{IFI}=.98, \mathrm{PNFI}=.78$, PGF1 $=.63$ ).

There was a statistically significant positive correlation between UGRS (43.21 \pm 16.25$)$ and TGRS. The internal consistency coefficient of the scale is $\alpha=.94$ and the internal consistency coefficient of subdimensions is $\alpha=.86$ (Meaning); $\alpha=.83$ (Relationships); $\alpha=.87$ (Opposite Cases); $\alpha=.89$ (Injustice); $\alpha=.80$ (Responses). The item-total correla- 
tion values were between .59 and .76 and the internal consistency coefficient varied between .92 and .93 when any item was removed. It was found that there was a positive directional correlation between pre-test $(43.68 \pm 17.71)$, carried out with four weeks interval to determine the invariance of UGRS against time, and post-test $(42.20 \pm 15.09)$ measurements and this relationship was statistically significant $(r=.89 ; \mathrm{p}=.000)$.

In conclusion, it is shown in light of scientific data that the validity and reliability analyzes of the UGRS meet the required values in the literature, it is a valid and reliable measurement tool and it does not have temporal change. With this study, a measurement tool has been introduced to literature in Turkey which can assess the grief rumination and the severity of grief. The use of UGRS in studies related to grief is important in order to evaluate the ruminative repetitive thinking patterns and the severity of the grief processes of individuals who have lost their loved one's such as spouses, children, siblings and parents. UGRS has appropriate psychometric properties to be used in studies related to grief and to determine the severity of grief. This scale is a measurement tool that can be used safely in future mourning, grief and ruminative grief studies in Turkey. The fact that this scale was studied in a non-clinical sample, limits the information obtained. For this reason, it is recommended that this scale be validated through clinical samples consisting of individuals who have lost a loved one.

\section{Kaynakça / References}

Aksayan, S. ve Gözüm, S. (2002). Kültürlerarası ölçek uyarlaması için rehber I: Ölçek uyarlama aşamaları ve dil uyarlaması. Hemşirelik Araştırma Dergisi, 4(1), 9-14.

American Psychiatric Association. (2013). Diagnostic and statistical manual of mental disorders (DSM-5). Washington, DC: American Psychiatric Publication.

Ayaz, T., Karanci, A. N. ve Aker, A. T. (2014). İki Boyutlu Yas Ölçeği'nin Türkçe formunun geçerlik ve güvenirlik çalışması. Türk Psikiyatri Dergisi, 25(4), 253-263.

Balcı-Çelik, S. (2006). Yas Ölçeği: Geçerlik ve güvenirlik çalışması. Türk Psikolojik Danışma ve Rehberlik Dergisi, 3(25), 105-114. 
Boelen, P. A., van den Bout, J. ve van den Hout, M. (2003). The role of negative interpretations of grief reactions in emotional problems after bereavement. Journal of Behavior Therapy and Experimental Psychiatry, 34, 225-238.

Büyüköztürk, Ş. (2017). Sosyal bilimler için veri analizi el kitabı. Ankara: Pegem Akademi.

Çapık, C. (2014). Geçerlik ve güvenirlik çalışmalarında doğrulayıcı faktör analizinin kullanımı. Anadolu Hemşirelik ve Sağlık Bilimleri Dergisi, 17(3), 196-205.

Clark, D. A. ve Rhyno, S. (2005). Unwanted intrusive thoughts in nonclinical individuals: Implications for clinical disorders. (D. A. Clark Ed.), Intrusive thoughts in clinical disorders: Theory, research, and treatment In (pp. 1-29). New York, NY, US: Guilford Press.

Crowley, S. L. ve Fan, X. (1997). Structural equation modeling: Basic concepts and applications in personality assessment research. Journal of personality assessment, 68(3), 508-531.

Doering, B. K., Barke, A., Friehs, T. ve Eisma, M. C. (2018). Assessment of grief-related rumination: validation of the German version of the Utrecht Grief Rumination Scale (UGRS). BMC psychiatry, 18(43), 1-13.

Durmuş, B., Yurtkoru, E. S. ve Çinko, M. (2011). Sosyal bilimlerde SPSS'le veri analizi. İstanbul: Beta Basım Yayın Dağıtım

Eisma, M. C., Schut, H. A. W., Stroebe, M. S., Stroebe, W., Boelen, P. A. ve van den Bout, J. (2013). Avoidance processes mediate the relationship between rumination and symptoms of complicated grief and depression following loss. Journal of Abnormal Psychology, 122, 961-970.

Eisma, M. C., Stroebe, M. S., Schut, H. A., Van Den Bout, J., Boelen, P. A., ve Stroebe, W. (2014). Development and psychometric evaluation of the Utrecht Grief Rumination Scale. Journal of Psychopathology and Behavioral Assessment, 36(1), 165-176.

Gökler-Danışman, I., Yalçınay, M. ve Yıldız, N. (2017). Measuring grief symptoms in cancer patients: The Reliability and validity study of the Turkish version of Prolonged Grief Disorder Scale. Turkish Journal of Psychiatry, 28(3), 190-197. 
Gülüm, V. İ. ve Dağ, İ. (2012). Tekrarlayıcı Düşünme Ölçeği ve Bilişsel Esneklik Envanterinin Türkçeye uyarlanması, geçerliliği ve güvenilirliği. Anatolian Journal of Psychiatry, 13, 216-223.

Hoe, S. L. (2008). Issues and procedures in adopting structural equation modeling technique. Journal of applied quantitative methods, 3(1), 76-83.

Hooper, D., Coughlan, J. ve Mullen, M. (2008). Structural equation modelling: Guidelines for determining model fit. The Electronic Journal of Business Research Methods, 6(1), 53-60.

Houwen, V. K., Stroebe, M., Schut, H., Stroebe, W. ve van den Bout, J. (2010). The mediating processes of bereavement: The role of rumination, threatening grief interpretations and deliberate grief avoidance. Social Science and Medicine, 71, 1669-1676.

Karagöz, Y. (2016). SPSS ve AMOS 23 uygulamal istatistiksel analizler. İstanbul: Nobel Yayınevi.

Keser, E. ve Işıklı, S. (2018). Yas ve Anlamı Yeniden Yapılandırma Envanteri'nin Türkçe Formu'nun psikometrik özelliklerinin incelenmesi. Düşünen Adam Psikiyatri ve Nörolojik Bilimler Dergisi, 31, 364-374.

Li, L. ve Schucany, W. R. (1975). Some properties of a test for concordance of two groups of rankings. Biometrika, 62(2), 417-423.

Lundorff, M., Holmgren, H., Zachariae, R., Farver-Vestergaard, I. ve O'Connor, M. (2017). Prevalence of prolonged grief disorder in adult bereavement: a systematic review and meta-analysis. J Affect Disord, 212, 138-49.

Munro, B. H. (2005). Statistical methods for health care research. Philadelphia: Lippincott Williams \& Wilkins.

Nolen-Hoeksema, S. (2001). Ruminative coping and adjustment to bereavement. (M. S. Stroebe, R. O. Hansson,W. Stroebe,\&H. Schut Eds.), Handbook of bereavement research: Consequences, coping and care In (pp. 545-562). Washington DC: American Psychological Association.

Pallant, J. (2010). SPSS: Survival manual. Berkshire, England: McGrawHill.

Patton, M. (2002). Qualitative research and evaluation methods. Thousand Oaks, CA: Sage. 
Robinson, M. S. ve Alloy, L. B. (2003). Negative cognitive styles and stress-reactive rumination interact to predict depression: A prospective study. Cognitive Therapy and Research, 27, 275-291.

Schreiber, J. B., Nora, A., Stage, F. K., Barlow, E. A. ve King, J. (2006). Reporting structural equation modeling and confirmatory factor analysis results: A review. The Journal of Educational Research, 99(6), 323-338.

Seçer, İ., Halmatov, S. ve Gençdoğan, B. (2013). Duygusal Tepkisellik Ölçeği'nin Türkçeye uyarlanması: Güvenirlik ve geçerlilik çalışması. Sakarya University Journal of Education, 3(1), 77-89.

Seçer, İ. (2015). Psikolojik test geliştirme ve uyarlama süreci SPSS ve LISREL uygulamaları. Ankara: Anı Yayıncilı.

Seçer, İ. (2017). SPSS ve LISREL ile pratik veri analizi analiz ve raporlaştırma. Ankara: Anı Yayıncilik.

Selvi, Y., Öztürk, R. I., Agargün, M. Y., Besiroglu, L. ve Çilli, A. S. (2011). Temel yas unsurlari ölçegi Türkçe formunun geçerlik ve güvenirlik çalismasi:Study of validity and reliability of the Turkish version of the core bereavement items. Noro-Psikyatri Arsivi, 48(2), 129-134.

Stroebe, M., Boelen, P. A., Van Den Hout, M., Stroebe, W., Salemink, E. ve Van Den Bout, J. (2007). Ruminative coping as avoidance. Eur Arch Psychiatry Clin Neurosci, 257(8), 462-72.

Stroebe, M., Schut, H. ve Stroebe, W. (2007) Health outcomes of bereavement. Lancet. 370(9603), 1960-1973.

Sukhodolsky, D. G., Golub, A. ve Cromwell, E. N. (2001). Development and validation of the Anger Rumination Scale. Personality and Individual Differences, 31, 689-700.

Sümer, N. (2000). Yapısal eşitlik modelleri: Temel kavramlar ve örnek uygulama. Türk Psikoloji Yazıları, 3(6), 49-73.

Tabachnick, B. G. ve Fidell, L. S. (2007). Using multivariate statistics. Boston, MA: Allyn \& Bacon/Pearson Education.

Tang, S., Eisma, M. C., Li, J. ve Chow, A. Y. (2018). Psychometric Evaluation of the Chinese version of the Utrecht Grief Rumination Scale (UGRS). Clinical psychology \& psychotherapy, 26(2), 262-272. 
van der Houwen, K., Stroebe, M., Schut, H., Stroebe, W. ve van den Bout, J. (2010). The mediating processes of bereavement: The role of rumination, threatening grief interpretations and deliberate griefavoidance. Social Science and Medicine, 71, 1669-1676.

Yıldırım, A. ve Şimşek, H. (2013). Sosyal bilimlerde nitel araştirma yöntemleri. Ankara: Seçkin Yayıncılık.

Yıldız, H. ve Cimete, G. (2011). Teksas Düzeltilmiş Yas Ölçeğinin uyarlama çalışması. Anadolu Psikiyatri Dergisi, 12(1), 30-36.

\section{Kaynakça Bilgisi / Citation Information}

Tekin, H. H. ve Kırlığlu, M. (2019). Utrecht Yasa Bağlı Ruminasyon Ölçeği'nin (UYRÖ) Türkçe Versiyonunun Geçerlilik ve Güvenirliği. OPUS-Uluslararası Toplum Araştırmaları Dergisi, 11(18), 1114-1135 DOI: 10.26466/opus.550290 
EK: Utrecht Yasa Bağlı Ruminasyon Ölçeği (UYRÖ)

\begin{tabular}{|c|c|c|c|c|c|}
\hline \multicolumn{6}{|c|}{$\begin{array}{l}\text { İnsanlar sevilen birinin ölümünden sonra sıklıkla çeşitli şeyleri düşünür. Son bir } \\
\text { ay süresince aşağıdaki sorularda yer alan ifadeleri ne sıklıkla düşündüğünüzü } \\
\text { öğrenmek istiyoruz. } 1 \text { "Hiç" anlamına gelmekte iken } 5 \text { "Çok Sık" anlamına } \\
\text { gelmektedir. Bu bağlamda vereceğiniz cevapları 1'den } 5 \text { 'e kadar derecelendirerek } \\
\text { cevap veriniz. }\end{array}$} \\
\hline \multicolumn{6}{|c|}{$\begin{array}{l}\text { 1. Son bir ay suresince onun olumunun sızın yaşaminıza } \\
\text { etkisini ne sıklıkla düşündünüz. }\end{array}$} \\
\hline \multicolumn{6}{|l|}{ 2. Son bir ay süresince kaybın sizin için ifade ettiği anlamı } \\
\hline $\begin{array}{l}\text { 3. Son bir ay süresince aile üyelerinden gereken desteği } \\
\text { alıp almadığınızı ne sıklıkla sorguladınız. }\end{array}$ & 1 & 2 & 3 & 4 & 5 \\
\hline & 1 & 2 & & 4 & 5 \\
\hline $\begin{array}{l}\text { 5. Son bir ay süresince bu kaybı hak edecek ne yaptığınızı } \\
\text { kendinize ne sıklıkla sordunuz. }\end{array}$ & 1 & 2 & 3 & 4 & 5 \\
\hline $\begin{array}{l}\text { 6. Son bir ay süresince bu kayıp hakkında tam olarak ne } \\
\text { hissettiğinizi ne sıklıkla düşündünüz. }\end{array}$ & 1 & 2 & 3 & 4 & 5 \\
\hline $\begin{array}{l}\text { 7. Son bir ay süresince bu kayba normal tepki verip ver- } \\
\text { mediğinizi ne sıklıkla sorguladınız. }\end{array}$ & 1 & 2 & 3 & 4 & 5 \\
\hline $\begin{array}{l}\text { 8. Son bir ay süresince eğer koşullar farklı olsaydı onun } \\
\text { ölümünün önlenip önlenemeyeceğini kendinize ne sıklıkla } \\
\text { sordunuz. }\end{array}$ & 1 & 2 & 3 & 4 & 5 \\
\hline \multicolumn{2}{|l|}{$\begin{array}{l}\text { 9. Son bir ay süresince arkadaşlarınızdan ve } \\
\text { tanıdıklarınızdan yeterli desteği alıp almadığınızı ken- } \\
\text { dinize ne sıklıkla sordunuz. }\end{array}$} & 2 & 3 & 4 & 5 \\
\hline $\begin{array}{l}\text { 10. Son bir ay süresince eğer başkaları farklı davransaydı } \\
\text { onun ölümünün önlenip önlenemeyeceğini kendinize ne } \\
\text { sıklıkla sordunuz. }\end{array}$ & 1 & 2 & 3 & 4 & 5 \\
\hline \multicolumn{2}{|l|}{$\begin{array}{l}\text { 11. Son bir ay süresince bu durumun neden bir başkasının } \\
\text { değil de sizin başınıza geldiğini ne sıklıkla düşündünüz. }\end{array}$} & 2 & 3 & 4 & 5 \\
\hline $\begin{array}{l}\text { 12. Son bir ay süresince bu kaybın adil olmadığı hakkında } \\
\text { ne sıklıkla düşündünüz. }\end{array}$ & 1 & 2 & 3 & 4 & 5 \\
\hline & 1 & 2 & 3 & 4 & 5 \\
\hline $\begin{array}{l}\text { 14. Son bir ay süresince diğer insanların kaybınız ile ilgili } \\
\text { nasıl davranmalarını istediğiniz hakkında ne sıklıkla } \\
\text { düşündünüz. }\end{array}$ & 1 & 2 & 3 & 4 & 5 \\
\hline $\begin{array}{l}\text { 15. Son bir ay süresince onun ölümüyle hayatınızın nasıl } \\
\text { değiştiğini ne sıklıkla düşündünüz. }\end{array}$ & 1 & 2 & 3 & 4 & 5 \\
\hline
\end{tabular}

